\title{
Lateral Hypothalamic Orexin/Hypocretin Neurons That Project to Ventral Tegmental Area Are Differentially Activated with Morphine Preference
}

\author{
Kimberlei A. Richardson ${ }^{1,2}$ and Gary Aston-Jones ${ }^{2}$ \\ 'Department of Pharmacology, Howard University College of Medicine, Washington, DC 20059 and 2Department of Neurosciences, Medical University of \\ South Carolina, Charleston, South Carolina 29425
}

\begin{abstract}
Orexin (or hypocretin) is synthesized exclusively in dorsomedial, perifornical, and lateral hypothalamus (LH). These neurons are implicated in several functions, including reward processing. We examined the ventral tegmental area (VTA) as a possible site of orexin action for drug preference during protracted morphine abstinence, and studied functional topography of orexin projections to VTA. Male Sprague Dawley rats were used to investigate whether orexin cells that project to VTA exhibit Fos activation with morphine conditioned place preference (CPP), and whether these cells exhibit increased Fos with morphine CPP during protracted abstinence. Unilateral injections of a retrograde tracer (WGA-Au, 350-400 nl) were made into the VTA or a nonreward area, locus ceruleus, and morphine or placebo pellets were implanted for $14 \mathrm{~d}$. Approximately 2 weeks after pellet removal (post dependence), CPP conditioning and testing were conducted. Triple labeling for WGA-Au, Fos, and orexin revealed that the percentage of VTA-projecting orexin neurons Fos activated on the CPP test day significantly increased in post-dependent (vs nondependent) rats, and was exclusive to LH orexin neurons (not dorsomedial or perifornical). Post-dependent animals showed a positive correlation between CPP scores and percentages of Fosactivated, caudal VTA-projecting LH orexin cells. Unlike afferents to caudal VTA, percentages of rostral VTA-projecting, LH orexin cells that were Fos activated showed a positive correlation with CPP only in nondependent animals. Fos in LC-projecting orexin cells was not correlated with CPP in any group. These results indicate that VTA is a heterogeneous and functionally significant target of orexin neurons for morphine reward during protracted abstinence.
\end{abstract}

\section{Introduction}

Orexin-A and -B (also known as hypocretin 1 and 2) are neuropeptides derived from a prepro-orexin molecule made exclusively in hypothalamic neurons (de Lecea et al., 1998; Sakurai et al., 1998). Studies demonstrated a role for these neurons in arousal, narcolepsy, and feeding (Chemelli et al., 1999; Lin et al., 1999; Peyron et al., 2000; Peyron and Charnay, 2003). Orexin neurons are activated by reward-associated stimuli in proportion to preference for drugs or food (Harris et al., 2005; Aston-Jones et al., 2009, 2010). This conditioned response to reward-associated stimuli was found for orexin neurons in the lateral orexin field (lateral hypothalamus; LH) but not dorsomedial hypothalamus $(\mathrm{DMH})$ or the perifornical area (PFA) (Harris and Aston-Jones, 2006).

Studies implicate orexins in drug-seeking behaviors and modulation of the mesolimbic dopamine (DA) system during reinforce-

\footnotetext{
Received July 30, 2011; revised Dec. 12, 2011; accepted Jan. 13, 2012.

Author contributions: K.A.R. and G.A.-J. designed research; K.A.R. performed research; K.A.R. analyzed data; K.A.R. and G.A.-J. wrote the paper.

Research was supported by Public Health Service Grants R37 DA06214 and C06 RR015455. We thank Dr. Rita Valentino for silver enhancement reagents, Dr. John Kwagyan for assistance with statistical analyses, Patricia Little for assistance with graphic illustrations, and Rebecca Fallon and Dr. Thressa Smith for excellent technical assistance.

Correspondence should be addressed to Dr. Gary Aston-Jones, Medical University of South Carolina, Department of Neuroscience, 173 Ashley Avenue, BSB 404, Charleston, SC 29425. E-mail: astong@musc.edu.

DOI:10.1523/JNEUROSCI.3917-11.2012

Copyright $\odot 2012$ the authors $\quad 0270-6474 / 12 / 323809-09 \$ 15.00 / 0$
}

ment (Borgland et al., 2009). Conditioned place preference (CPP) for morphine and cue- or stress-induced reinstatement of ethanol or cocaine seeking were blocked by the orexin-1 receptor antagonist SB-334867 (Boutrel et al., 2005; Harris et al., 2005; Lawrence et al., 2006; Richards et al., 2008; Aston-Jones et al., 2009; Smith et al., 2009, 2010; Lawrence, 2010). SB-334867 blocked behavioral sensitization to cocaine and synaptic plasticity in the ventral tegmental area (VTA) (Borgland et al., 2006) and attenuated behaviors associated with morphine withdrawal (Li et al., 2010). SB-334867 also reduced the progressive ratio breakpoint for cocaine as well as baseline and cocaine-induced accumbal DA (España et al., 2010). Orexin microinjected into VTA increased effects of cocaine on DA signaling and cocaine self-administration (España et al., 2011).

VTA is a key region for behavioral responding to rewards and reward-associated stimuli, and is an important site for orexin actions in reward processing. VTA receives orexin projections (Nakamura et al., 2000; Peyron et al., 2000; Fadel and Deutch, 2002). Orexin microinjected into VTA increases neuronal firing (Korotkova et al., 2003) and DA release in VTA targets (Narita et al., 2006; Vittoz and Berridge, 2006; Vittoz et al., 2008) and reinstates morphine CPP (Harris et al., 2005). In addition, orexin projections that target VTA are critical for acquisition of morphine-stimulus associations (Narita et al., 2006; Harris and Aston-Jones, 2007).

Protracted withdrawal (2-5 weeks of forced abstinence) from morphine or cocaine increased drug reward, as evidenced by in- 
creased morphine preference in CPP tests (Harris and AstonJones, 2003a). Rats subjected to morphine CPP during protracted withdrawal showed more Fos-positive, LH orexin neurons than nondependent rats and Fos induction was proportional to preference (Aston-Jones and Harris, 2004; Aston-Jones et al., 2010), leading us to propose that preference during withdrawal involves these orexin neurons. Therefore, our aim was to test whether VTA is an important site for orexin during protracted withdrawal. Retrograde tracing combined with double label immunohistochemistry showed increased Fos activation of VTA-projecting orexin cells with morphine CPP during protracted withdrawal. Additionally, the functional topography of orexin projections to caudal and rostral VTA versus an area less directly linked with reward (locus ceruleus; LC) was compared. Our results indicate that VTA is a heterogeneous target site for orexin actions during protracted withdrawal.

\section{Materials and Methods}

Animals. Male Sprague Dawley rats (VTA injections $n=8$ /group, LC injections $n=7 /$ group, 300-350 g; Charles River) were pair-housed in a reversed $12 \mathrm{~h}$ light/dark cycle (lights off 6 A.M.), temperature- and humidity-controlled room in an Association for Assessment and Accreditation of Laboratory Animal Care accredited animal facility at the Medical University of South Carolina. The rats were given ad libitum access to food and water. All experiments were approved by the Institutional Animal Care and Use Committee at the Medical University of South Carolina and conducted according to specifications of the National Institutes of Health as outlined in the Guide for the Care and Use of Laboratory Animals.

Rats were periodically handled and weighed before and during the studies. Rats implanted with morphine pellets showed a reduction in weight $(8-10 \mathrm{~g})$ after pellet implantation and after withdrawal, but the weights of these rats recovered within a week post withdrawal. Animals implanted with placebo pellets did not show a reduction in weight. Although food intake was not monitored, there was no statistically significant difference in body weight gain between nondependent and postdependent rats during CPP conditioning and testing. All rats were alert and active during the dark cycle and cage activity was decreased during the rest period (light cycle). There were no apparent differences in overt sleep-wake patterns between these groups.

Drugs. Morphine pellets and morphine sulfate powder were provided by the National Institute on Drug Abuse (Baltimore, MD). Morphine powder was dissolved in sterile saline and administered via intraperitoneal injection. All vehicle injections consisted of sterile saline.

Chronic drug treatment. Rats were subcutaneously implanted under isoflurane anesthesia with two $75 \mathrm{mg}$ of morphine tablets to induce morphine dependence, as in previous studies from this lab (Harris and Aston-Jones, 2003a,b). Nondependent control rats were implanted at the same time with similar but inert placebo pellets (provided by the $\mathrm{Na}-$ tional Institute on Drug Abuse). This procedure for implantation of morphine pellets has been shown to be a reliable way to induce physical dependence (Yoburn et al., 1985; Gold et al., 1994; Delfs et al., 2000). The pellets dissolve by day 14 as the signs of physical dependence wane (Gold et al., 1994; Harris and Aston-Jones, 2001). Any pellet remnants were aspirated after $14 \mathrm{~d}$ to induce forced abstinence, and animals remained in their home cages until CPP conditioning 2 weeks later.

Retrograde tracer injections. One week before implantation of the morphine or placebo pellets, rats were anesthetized with ketamine/xylazine $(56.5 / 8.7 \mathrm{mg} / \mathrm{kg})$ and placed in a stereotaxic frame. An injection of meloxicam $(1 \mathrm{mg} / \mathrm{ml})$, a nonsteroidal anti-inflammatory analgesic, was administered before surgery. Unilateral injections were made into either LC or VTA with the retrograde tracer, colloidal gold conjugate of wheat germ agglutinin coupled to inactive horseradish peroxidase (WGA-Au; EY Laboratories). WGA-Au (350-400 nl, $10 \mathrm{~nm}$ gold particle size) was microinjected via a glass micropipette (tip diameter 10-20 $\mu \mathrm{m}$ ) into LC ( $4 \mathrm{~mm}$ caudal to lambda), rostral VTA $(-4.68$ to $-5.04 \mathrm{~mm}$ from bregma), or caudal VTA ( -5.76 to $-6.24 \mathrm{~mm}$ from bregma) using brief pulses of pneumatic pressure (Picospritzer; General Valve). The pipette remained in position an additional 15 min post injection to limit the spread of the tracer along the pipette tract for all injections. After the pipette was withdrawn, the incision was sutured and cefazolin $(100 \mathrm{mg} /$ $\mathrm{ml}$ ) was administered intramuscularly. Rats were periodically handled and weighed before beginning the CPP procedure.

CPP procedure. The CPP procedure occurred 2 weeks after pellet removal using an unbiased design, as in previous reports from this lab (Harris and Aston-Jones, 2001, 2003a). A Plexiglas apparatus with two distinct compartments, separated by a Plexiglas divider, was used for conditioning and testing. Each compartment was equipped with photobeams permitting time and activity in each compartment to be automatically assessed (MED Associates). The first compartment had a rod floor with black walls, and the second compartment had a mesh floor with black and white stripes on the walls. Three days after a baseline preconditioning test, animals were given alternating injections of morphine (10 $\mathrm{mg} / \mathrm{kg}$ ) or saline ( $1 \mathrm{ml} / \mathrm{kg}$, i.p.) and confined to one compartment for 30 min (twice daily injections at least $6 \mathrm{~h}$ apart, e.g., morphine A.M., saline P.M., alternating order of pairings for each session for $3 \mathrm{~d}$ ). Two days after the third conditioning day, animals were tested for morphine preference for $15 \mathrm{~min}$ with access to both sides of the chamber; no injections were given on this test day.

Perfusion. Ninety minutes after the preference test, animals were deeply anesthetized with ketamine/xylazine $(56.5 / 8.7 \mathrm{mg} / \mathrm{kg}$, i.p.) and transcardially perfused with $0.9 \%$ saline followed by ice-cold $4 \%$ PFA in $0.1 \mathrm{M}$ PBS, pH 7.4. The brains were removed and stored overnight in $4 \%$ PFA. They were then transferred to a $30 \%$ sucrose solution and stored at $4^{\circ} \mathrm{C}$ for $5 \mathrm{~d}$. Coronal sections $(40 \mu \mathrm{m})$ were cut using a cryostat. Sections from placebo- and morphine-pelleted animals were processed together for silver intensification of WGA-Au and orexin-A and Fos immunohistochemistry to equalize staining between groups.

Histochemical processing of WGA-Au. Sections from rats injected with WGA-Au were processed using the IntenSE BL silver enhancement kit (GE Healthcare) or Aurion R-Gent silver enhancement kit (Electron Microscopy Sciences) to localize the transported gold-protein conjugate. After this reaction for WGA-Au, the same sections were stained for Fos and orexin as follows.

Immunohistochemical processing for Fos and orexin. Sections were processed for Fos and orexin-A immunohistochemistry as previously described (Harris et al., 2005). Briefly, sections were placed in $0.3 \% \mathrm{H}_{2} \mathrm{O}_{2}$ to quench endogenous peroxidases, followed by three PBS washes and then placed in a solution of $0.1 \mathrm{M}$ PBS with $0.3 \%$ Triton-X (PBST, pH 7.4) containing $2 \%$ normal donkey serum for $2 \mathrm{~h}$. Sections were incubated overnight at room temperature in this same solution with the addition of primary antibody (rabbit antiserum against Fos-related antigens at 1:2000, SC-52;Santa Cruz Biotechnology). Sections were rinsed three times in PBST and then incubated for $2 \mathrm{~h}$ with the secondary antibody (biotinylated donkey anti-rabbit 1:500; Jackson ImmunoResearch Laboratories) the following day. After three rinses in PBST, sections were transferred to an avidin-biotin complex (ABC, 1:500; Vector Laboratories) for $1.5 \mathrm{~h}$. Following the $\mathrm{ABC}$ incubation, sections were rinsed two times with PBST and once with $0.05 \mathrm{M}$ Tris buffer. Fos cells were visualized by placing the sections in 3,3-diaminobenzidine (DAB, $0.02 \%$; Sigma) with $0.0002 \% \mathrm{H}_{2} \mathrm{O}_{2}$ and $0.6 \%$ nickel ammonium sulfate in $0.01 \mathrm{M}$ Tris buffer for $5.5 \mathrm{~min}$. This reaction was stopped by rinsing the sections in Tris buffer, followed by three PBS rinses. The sections were incubated in PBS-azide for $45 \mathrm{~min}$ and then placed into primary antibody for orexin-A (1:1500, SC8070;Santa Cruz Biotechnology) overnight at room temperature. The following day, the sections were rinsed three times in PBST and then incubated in secondary antibody (biotinylated donkey anti-goat 1:500; Jackson ImmunoResearch Laboratories) for $2 \mathrm{~h}$. After three rinses in PBST sections were transferred to an ABC (1:500; Vector Laboratories) for $1.5 \mathrm{~h}$. Following the $\mathrm{ABC}$ incubation, sections were rinsed two times with PBST and once with $0.05 \mathrm{M}$ Tris buffer. Orexin cells were visualized by placing the sections in DAB $(0.02 \%$; Sigma) with $0.0002 \% \mathrm{H}_{2} \mathrm{O}_{2}$ for $2.5 \mathrm{~min}$. This reaction was stopped by rinsing the sections in Tris buffer, followed by three PBS rinses. The sections were mounted on gelatin-coated slides, dehydrated through graded alcohols, cleared in xylene, and coverslipped with Permount. Orexin-positive neurons exhibited brown cytoplasmic staining, Fos-positive nuclei (nickel 
intensified) were stained black, and WGA-Au-positive cells had dark punctate cytoplasmic staining.

Verification of injection sites. Sections from VTA injection sites were processed for silver intensification of WGA-Au followed by counterstaining with neutral red or methyl green to visualize brain structures. Sections from LC injection sites were processed for silver intensification of WGA-Au followed by tyrosine hydroxylase immunohistochemistry as previously described (Harris and Aston-Jones, 2007) or counterstained with neutral red.

Quantification of labeled cells. OpenLab software (PerkinElmer) was used to count the various types of labeled cells. A pointer tool in the software enabled each cell of interest to be counted and marked, preventing a cell from being counted twice. The cells were counted directly from a color image on a screen that was acquired from a digital camera attached to a microscope (DMRXA; Leica). Two sections from each animal were counted. Sections from two different hypothalamic levels were counted and averaged for each animal. The levels chosen corresponded to the following distances from bregma: -2.76 and -3.36 from bregma (Paxinos and Watson, 2007).

A factorial design was used to examine the impact of injection site and hypothalamic region, and the effect of treatment on percentage labeling for different markers. Cross-product terms were included in the models to examine any potential interaction. All $2 \times 2$ interactions among treatment, injection site, and hypothalamic region were included in the models. The mathematical model for the generalized linear model has the form $Y_{i}=b_{0}+b_{1} X_{1}+b_{2} X_{2}+b_{3} X_{3}+b_{12} X_{1} X_{1}+b_{13} X_{1} X_{3}+b_{23} X_{2} X_{3}$ where $Y_{i}$ is the percentage labeling; $b_{j}$ is the regression coefficient for the main effects and $b_{j k}$ is the regression coefficient of the interaction $(j, k=$ $0,1,2,3 ; j<\mathrm{k}) ; \mathrm{X}_{1}, \mathrm{X}_{2}$, and $\mathrm{X}_{3}$ represent the main effect due to treatment $\left(\mathrm{X}_{1}\right)$, injection site $\left(\mathrm{X}_{2}\right)$, and hypothalamic region $\left(\mathrm{X}_{3}\right)$; and $\mathrm{X}_{\mathrm{j}} \mathrm{X}_{\mathrm{k}}$ represents their interaction $(\mathrm{j}, \mathrm{k}=1,2,3 ; \mathrm{j}<\mathrm{k})$. Separate analyses were done for \%orexin + WGA-Au cells that are also Fos activated (\%triple labeled/ total orexin + WGA-Au double labeled), \%orexin cells with Fos activation that have WGA-Au (\%triple labeled/total orexin + Fos double labeled), \%orexin cells with Fos (\%orexin + Fos-labeled neurons/total orexin neurons), and \%WGA-Au cells with Fos (\%WGA + Fos/total WGA neurons). Whenever the interaction terms showed statistical significance, pairwise comparisons were performed to examine differences within groups using the Wilcoxon rank sum test. Correlation coefficients for the comparisons of percentages of activated VTA- or LC-projecting orexin neurons and the corresponding preference score for each animal were calculated and statistical significance was determined $(p<0.05)$.

\section{Results}

\section{Orexin cell fields and retrograde labeling from VTA}

Numerous orexin-immunoreactive neurons and varicosities were found in the areas of DMH, PFA, and LH, as previously reported (Peyron et al., 1998; Scammell et al., 2000). Retrogradely labeled neurons after injections of WGA-Au in VTA were also noted throughout this region. Qualitative analyses revealed no apparent topographic segregation in the dorsoventral or rostrocaudal planes for WGA-Au-labeled neurons in DMH and LH. However, it appeared that retrogradely labeled neurons located in PFA were preferentially located somewhat ventrally (i.e., near the dorsal edge of the fornix). The overall results and comparisons for Fos activation of LH orexin neurons retrogradely labeled from caudal versus rostral VTA are given below. Figure 1 illustrates orexin neurons retrogradely labeled from VTA that were Fos activated after morphine CPP.

\section{Orexin afferents to caudal VTA}

Orexin neurons that project to caudal VTA are Fos activated by morphine CPP in post-dependent animals

Figure 2 shows that orexin neurons that project to caudal VTA are Fos activated after morphine CPP. Wilcoxon rank sum test revealed differences between treatment groups in the percentage orexin neurons retrogradely labeled from caudal VTA that were Fos activated (triple labeled/total orexin + WGA-Au double labeled). Importantly, there was a significantly greater percentage of orexin neurons

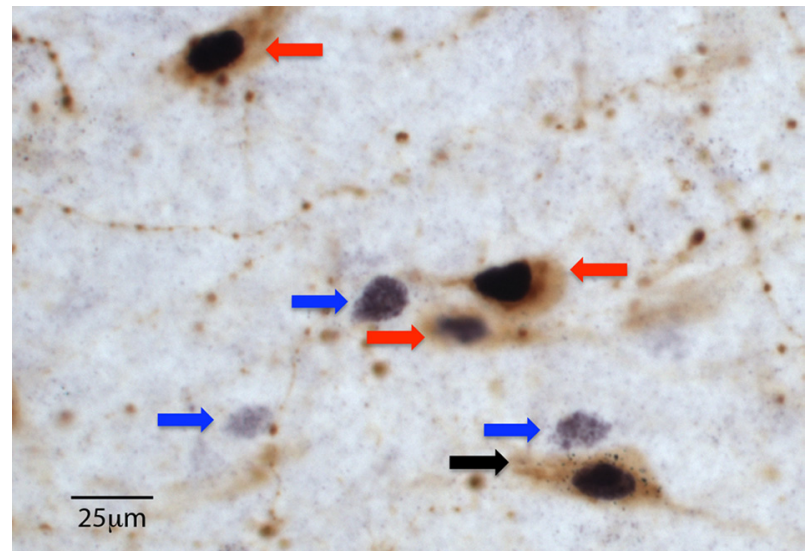

Figure 1. Triple-labeled neurons in LH. Photo showing a VTA-projecting (i.e., retrogradely labeled) orexin neuron that was Fos activated after morphine (PP (black arrow). The photo also shows single-labeled Fos-positive cells (blue arrows) or double-labeled orexin + Fos-positive neurons (red arrows) in close proximity to the triple-labeled neuron. Fos appears black in nuclei, orexin appears brown in cytoplasm, and the WGA-Au tracer appears as black particles in cytoplasm. Scale bar, $25 \mu \mathrm{m}$.

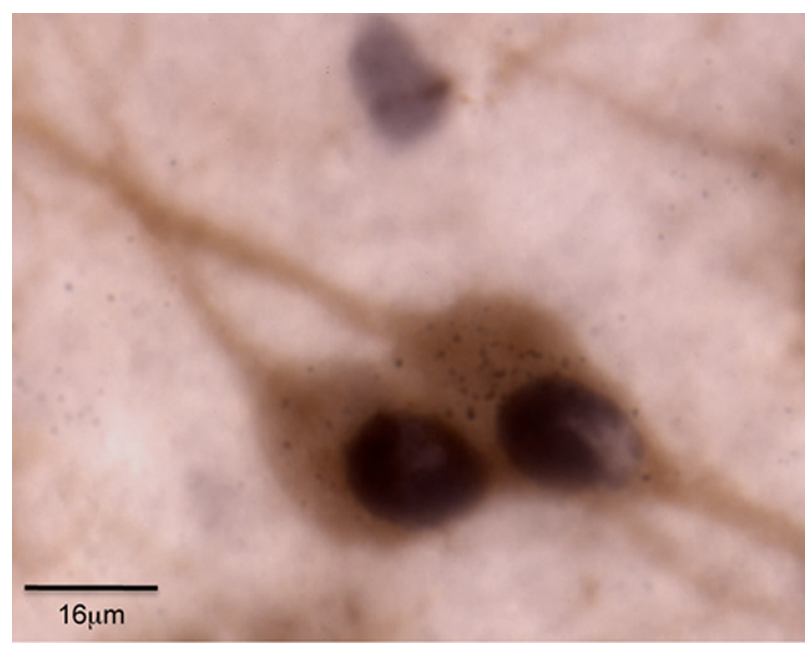

Figure 2. Photo shows two orexin cells that were Fos activated after morphine CPP testing and retrogradely labeled from a WGA-Au microinjection in caudal VTA. Scale bar, $16 \mu \mathrm{m}$.

that project to caudal VTA that were Fos activated by morphine CPP in the LH of post-dependent animals versus nondependent animals $(28.1 \% \pm 3.2$ vs $15.5 \% \pm 3.7, n=8 /$ group,$p<0.05)$. There were no significant differences in the percentages of caudal VTA-projecting orexin neurons that were Fos activated after morphine CPP for postdependent rats versus nondependent rats in $\mathrm{DMH}(33.0 \pm 9$ vs $18.75 \pm 5.4, n=8$ /group) or PFA (16.7 \pm 6.4 vs $21.4 \pm 6.3, n=$ 8 /group), but there was a trend apparent for an increase in Fos activation in $\mathrm{DMH}(p=0.08)$.

\section{Topography of Fos-activated orexin neurons that project to caudal VTA}

As described above, we determined that the Fos activation of caudal VTA-projecting orexin neurons by morphine CPP was exclusive to $\mathrm{LH}$, and did not occur significantly in DMH or PFA. Also, the percentages of caudal VTA-projecting, LH orexin neurons that were Fos activated were significantly correlated with the intensity of conditioned preference in post-dependent animals $(r=0.65, p<0.05$; Fig. $3 A)$. Thus, as preference scores increased in post-dependent rats, the percentage of caudal VTA-projecting, $\mathrm{LH}$ orexin neurons that were Fos activated increased. There was no 
such correlation in the percentage of caudal VTA-projecting DMH and PFA orexin neurons with Fos activation and preference scores (Fig. 3A). Additionally, there was no significant correlation for similarly labeled neurons in $\mathrm{LH}, \mathrm{DMH}$, or PFA for neurons retrogradely labeled from caudal VTA in nondependent animals (Fig. 3B).

The results from the above studies were obtained using microinjections of WGA-Au into caudal VTA [between levels -5.76 and $-6.24 \mathrm{~mm}$ using the Paxinos and Watson (2007) atlas, at or caudal to interpeduncular nucleus]. Diagrams in Figure 3 indicate the levels of injections (Fig. $3 C$ ) and the maximum and minimum spread of WGA-Au throughout the region (Fig. 3D). Data from injections outside of the caudal VTA were excluded from immunohistochemistry and quantification.

\section{Orexin afferents to rostral VTA}

As VTA is functionally and anatomically heterogeneous, we sought to determine in the next set of experiments whether orexin neurons that project to rostral VTA were also Fos activated by morphine conditioning. Injections in rostral VTA yielded apparently similar percentages of Fos-activated, retrogradely labeled orexin neurons in $\mathrm{LH}$ as injections into caudal VTA (for nondependent rats, caudal vs rostral VTA is $15.5 \pm$ 3.7 vs $20.7 \pm 3.1$ and for post-dependent rats, caudal vs rostral VTA is $28.1 \pm 3.2$ vs $30.8 \pm 2.4$ ). However, rostral VTA injections produced greater percentages of Fos labeling in PFA and DMH orexin neurons, versus caudal VTA injections, as confirmed by an interaction between injection site and hypothalamic region in overall analyses (below).

In addition, rostral and caudal injections yielded different labeling in post-dependent animals versus nondependent animals. A Wilcoxon rank sum test revealed differences in percentage orexin neurons retrogradely labeled from rostral VTA that were Fos activated between treatment groups. The percentage of rostral VTAprojecting orexin cells that were Fos activated (triple labeled/total orexin + WGA-Au double-labeled neurons) after morphine CPP in post-dependent rats was significantly greater than the percentage in nondependent rats $(30.8 \% \pm 2.4$ vs $20.7 \% \pm 3.1, n=8$ /group, $p<$ $0.05)$ in the LH. There was no significant difference in orexin neurons that projected to rostral VTA that were Fos activated after morphine CPP in DMH or PFA. These results indicate that LH orexin neurons that project to either rostral or caudal VTA are strongly activated by stimuli associated with morphine during the protracted withdrawal state.

However, in contrast to the above data for caudal VTAprojecting orexin neurons, the percentage of rostral VTA-projecting LH orexin neurons that were Fos activated in animals that underwent CPP conditioning in nondependent subjects was significantly correlated with the amount of conditioned preference (Fig. 4A, $r=$ $0.66, p<0.05$ ), whereas the percentage of rostral VTA-projecting, $\mathrm{LH}$ orexin neurons that were Fos activated in animals that underwent CPP conditioning in post-dependent rats did not correlate with the amount of conditioned preference (Fig. 4B).

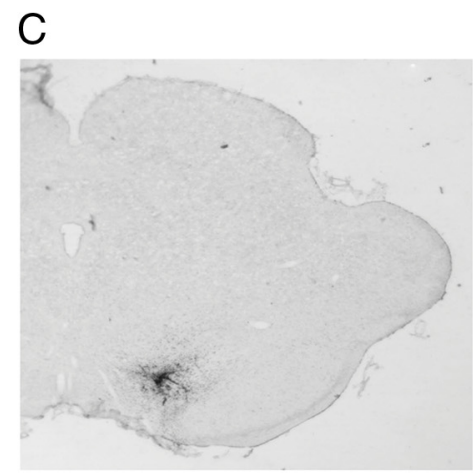

D

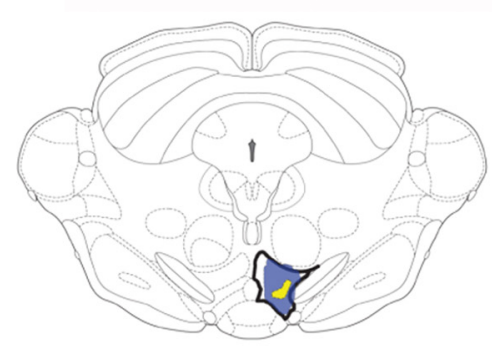

Figure 3. Caudal VTA-projecting neurons: correlations with preference. $\boldsymbol{A}, \mathrm{A}$ significant positive correlation occurred between rats ( $n=8$ /group). C, Photo demonstrating WGA-Au injection in caudal VTA. $\boldsymbol{D}$, Schematic of a frontal section illustrating the maximum (blue) and minimum (yellow) spread of WGA-Au for caudal VTA injections (dorsal up).

The greater percentage of Fos activation in rostral VTAprojecting orexin neurons in post-dependent rats versus nondependent rats was only evident in orexin neurons located in $\mathrm{LH}$, similar to results from caudal VTA injections $(30.8 \% \pm$ 2.4 vs $20.7 \pm 3.1, p<0.05)$. The percentages of VTAprojecting orexin neurons that were Fos + (triple labeled/total orexin + WGA-Au double labeled) in $\mathrm{LH}$, but not those in $\mathrm{DMH}$ or PFA, correlated with morphine preference in nondependent animals (Fig. $4 A ; r=0.66, p<0.05$ ). The percentages of rostral VTA-projecting orexin neurons that were Fos activated in PFA or DMH of nondependent animals that underwent CPP conditioning were not correlated with the amount of conditioned preference. Also, the percentages of rostral VTA-projecting orexin neurons that were Fos activated in $\mathrm{LH}$, PFA, or DMH of post-dependent animals that underwent CPP conditioning were not correlated with the amount of conditioned preference (Fig. $4 \mathrm{~B}$ ). These results extend those for caudal VTA injections by showing topography both at the level of VTA (rostral vs caudal) and hypothalamus (LH vs PFA/ $\mathrm{DMH}$ ) for orexin regulation of reward processing.

These results were obtained using microinjections of WGA-Au into rostral VTA [between levels -4.68 and $-5.04 \mathrm{~mm}$ from bregma using the Paxinos and Watson (2007) atlas, anterior to interpeduncular nucleus]. Diagrams in Figure 4 indicate the levels of injections in rostral VTA (Fig. 4C) and the maximum and minimum spread of injected WGA-Au (Fig. 4D). Data from injections outside of VTA were excluded from immunohistochemistry and quantification. 

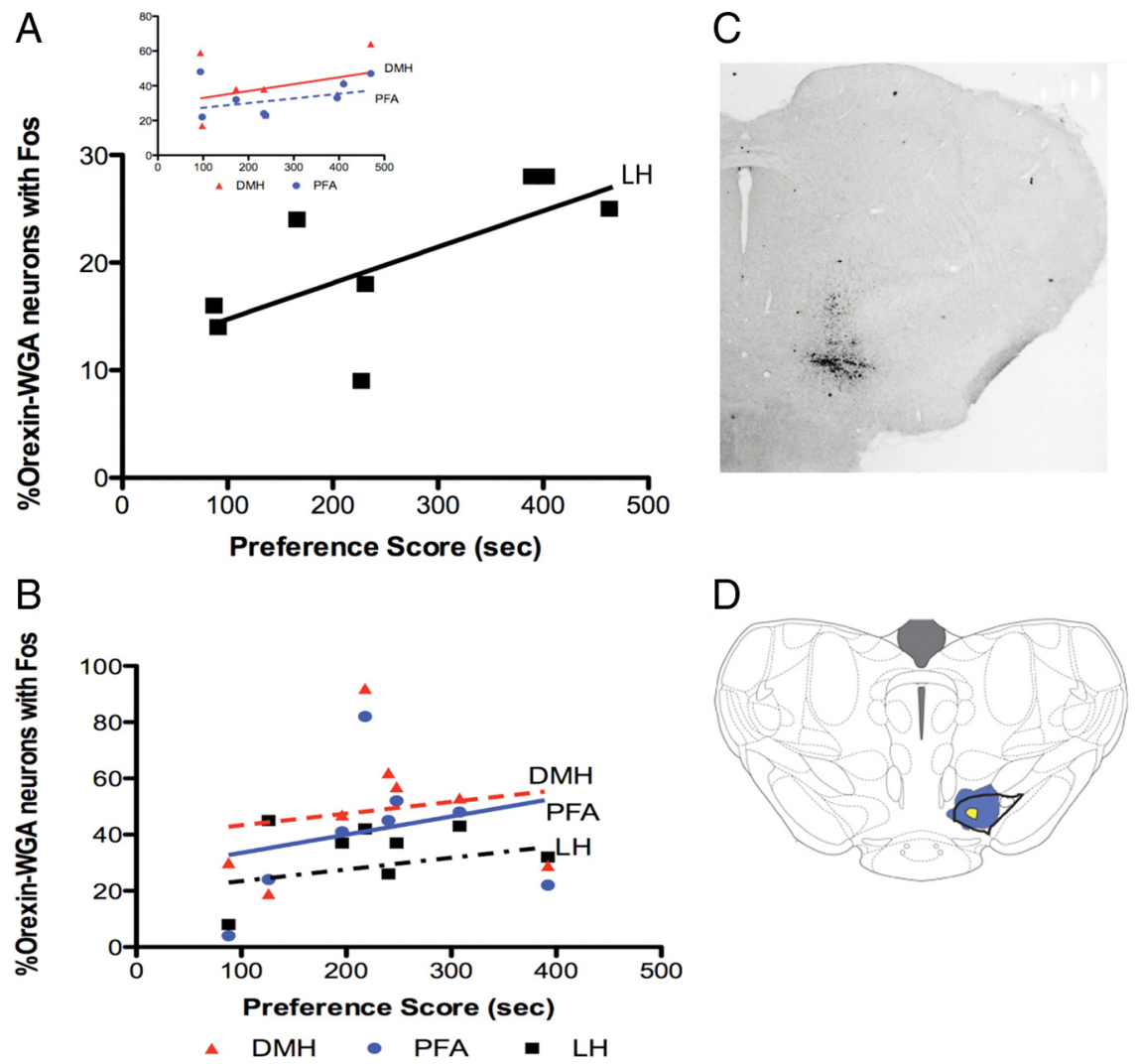

Figure 4. Rostral VTA-projecting neurons: correlations with preference. $A$, A significant positive correlation occurred between the percentage Fos activation of $L H$ orexin neurons labeled from rostral VTA injections and preference scores in nondependent rats ( $p<0.05, n=8$ per group). No such correlation was found in DMH or PFA (inset). $\boldsymbol{B}$, No significant correlation was found between Fos activation of orexin neurons labeled from rostral VTA and preference scores in LH, DMH, or PFA for post-dependent rats $(n=$ 8/group). C, Photo demonstrating WGA-Au injection in rostral VTA (bregma $\sim 4.8 \mathrm{~mm}$ ). D, Schematic of a frontal section illustrating the maximum (blue) and minimum (yellow) spread of WGA-Au for rostral VTA injections (dorsal up).

\section{Orexin afferents to $\mathrm{LC}$}

We were also interested in determining whether LH orexin neurons, that project to an area less directly linked with reward (e.g., LC), were activated by morphine preference testing. WGA-Au was injected into LC unilaterally in animals ( $n=7 /$ group) that were subjected to morphine or placebo pellet treatment and CPP as described above. In contrast to VTA-projecting, LH orexin neurons, there were no significant differences in percentages of orexin neurons retrogradely labeled from LC that were Fos activated (triple labeled/total orexin + WGA-Au double labeled) in post-dependent rats versus nondependent rats in $\mathrm{LH}(21.7 \pm 2.9$ vs $31.4 \pm 4.9), \mathrm{DMH}(68.7 \pm 3.5$ vs $61.1 \pm 7)$, or PFA $(45.1 \pm 3.5$ vs $36.1+6.4)$.

The percentages of LC-projecting orexin neurons that were Fos positive in $\mathrm{LH}, \mathrm{DMH}$, or PFA of animals that underwent CPP conditioning in nondependent subjects did not correlate with the amount of conditioned preference (Fig. 5A). Also, the percentages of LC-projecting, LH orexin neurons in animals that underwent CPP conditioning during protracted morphine withdrawal (i.e., post-dependent rats) that were Fos positive did not correlate with the amount of conditioned preference (Fig. 5B). Figure 5 illustrates the locations of WGA-Au injections in LC (Fig. 5C,D). Data from injections centered outside of LC were excluded from immunohistochemistry and quantification.

The results from these studies indicate that LH orexin neurons that project to a reward area (rostral or caudal VTA), but not those that project to a nonreward area (LC), are significantly activated by stimuli previously associated with morphine.
Retrogradely labeled orexin neurons are Fos activated in post-dependent animals: overall analysis of \%triple labeled/total orexin + WGA double-labeled neurons

This comparison was to analyze whether orexin neurons that were retrogradely labeled from different targets were Fos activated in post-dependent and nondependent animals. A main effect of treatment (postdependent vs nondependent, $F_{(1,1)}=5.42$, $p<0.05$ ), injection site (caudal VTA vs rostral VTA vs LC, $\left.F_{(2,1)}=21.69, p<0.0001\right)$, hypothalamic region (DMH vs PFA vs $\mathrm{LH}$, $\left.F_{(2,1)}=19.86, p<0.0001\right)$, and an interaction between the hypothalamic region and injection site $\left(F_{(4,1)}=4.76, p<0.005\right)$ was observed for the percentage of orexin cells with WGA that are Fos activated. A Wilcoxon test revealed that rostral VTA injections yielded a greater percentage of triple-labeled cells in DMH and PFA (of all orexin + WGA double-labeled neurons) than caudal VTA injections. No other significant interactions were found.

\section{Fos-activated orexin neurons are} retrogradely labeled from caudal VTA: overall analysis of \%triple labeled/total orexin + Fos double-labeled neurons This comparison was to analyze whether Fos-activated orexin neurons were likely to be retrogradely labeled from different targets in post-dependent and nondependent animals. We found that a significantly higher percentage of $\mathrm{LH}$, orexin Fos-activated neurons were retrogradely labeled from caudal VTA (triple labeled/total orexin + Fos double labeled) in postdependent rats compared with nondependent animals (32.1 \pm 4.3 vs $19.8 \pm 4.6, p<0.05, n=8$ /group). In addition, the percentages of Fos-activated, LH orexin neurons that project to caudal VTA were significantly correlated with the expression of preference in post-dependent animals $(r=0.88, p<0.005)$. Significant correlations were not found in nondependent animals in any orexin cell region. Similarly, no significant correlations were found for Fos-activated orexin neurons retrogradely labeled from rostral VTA or LC.

Analyses of these data (\%triple labeled/total orexin + Fos double-labeled neurons) revealed a main effect of injection site $\left(F_{(2,1)}=7.82, p<0.001\right)$ and hypothalamic region $\left(F_{(2,1)}=\right.$ $10.93, p<0.0001)$, but not of treatment, and an interaction between injection site and hypothalamic region $\left(F_{(4,1)}=5.57\right.$, $p<0.0005)$. Also, rats with WGA-Au injections in caudal VTA exhibited a higher percentage $(p<0.05)$ of Fos-activated orexin neurons with WGA in LH than animals with rostral VTA injections.

Percentage of Fos-activated retrogradely labeled hypothalamic neurons did not differ between cells projecting to VTA versus LC: overall analysis of \%WGA + Fos double-labeled neurons/total WGA neurons

This comparison was to analyze the percentages of neurons (including orexin and non-orexin cells) retrogradely labeled from 
different targets in post-dependent and nondependent animals that were Fos activated. With respect to the activation of neurons projecting to caudal VTA, rostral VTA, or LC (comparisons, caudal VTA vs rostral VTA; caudal VTA vs LC; or rostral VTA), there was no main effect of treatment, injection site, or hypothalamic region on the percentage of WGA-positive cells that were Fos activated. There was no significant difference in the percentage of Fos-activated cells with WGA-Au tracer in dependent rats versus nondependent rats. This indicates that prior drug exposure had no effect on the uptake of WGA-Au tracer into Fos-activated cells.

\section{Fos activation of orexin neurons varies} with treatment and hypothalamic region: overall analysis of \%orexin + Fos double-labeled neurons/total orexin neurons

This comparison was conducted with respect to the entire orexin neuron population across hypothalamic regions, including orexin cells with WGA-Au and those without WGA-Au labeling. There was a main effect of drug treatment on the percentage of orexin cells that were Fos activated $\left(F_{(1,1)}=\right.$ 14.23, $p<0.0005)$. Similarly, the hypotha-

lamic region $\left(F_{(2,1)}=61.73, p<0.0001\right)$ had a main effect on Fosactivated orexin cells. The data from these analyses confirm previous work (Aston-Jones et al., 2009) from our lab demonstrating that the percentage of orexin neurons that are Fos activated after morphine CPP is greater in dependent rats versus nondependent rats $(p<$ 0.05) across each hypothalamic region.

\section{Discussion}

The results from this study implicate projections from hypothalamic orexin neurons to VTA nuclei in morphine reward during protracted abstinence. Our lab previously demonstrated that orexin neurons in LH become Fos activated by a CPP test for drug or food preference (Harris et al., 2005). Our present study extends those results by demonstrating: (1) the influence of prior drug exposure on activation of orexin cells by morphine CPP, (2) that LH orexin neurons that are Fos activated by morphine CPP project to the VTA, and (3) that prior drug exposure affects which VTA neural system (caudal vs rostral) is associated with preference.

A positive correlation was found in post-dependent animals between drug preference and the percentage of Fos-activated, caudal VTA-projecting LH orexin cells. This correlation was not found for afferents to rostral VTA; instead, a positive correlation was found between the percentage of Fos-activated, rostral VTAprojecting LH orexin cells and preference only in nondependent animals. No correlations were found between Fos-activated, VTA-projecting orexin neurons in PFA or DMH and preference in either nondependent or post-dependent subjects. Also, no significant correlation existed for Fos activation in LC-projecting orexin cells in nondependent or post-dependent animals and preference. Together, these results indicate that VTA is a functionally significant target of orexin neurons for morphine reward, and different sets of orexin neurons are engaged by

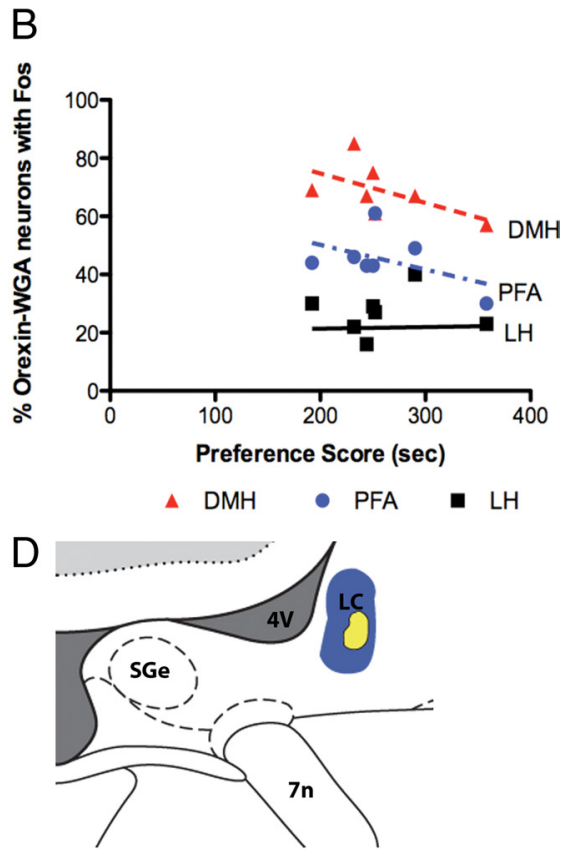

igure 5. Fos activation in LC-projecting orexin neurons. $\boldsymbol{A}$, There were no significant correlations for the percentages of orexin neurons that were Fos positive and preference scores in nondependent rats. $\boldsymbol{B}$, There were no significan illustrating across all cases the dense core (blue) and halo (yellow) for WGA-Au injections in LC (dorsal up). LC, locus ceruleus; 4V, fourth ventricle; $S G$, supragenual nucleus; $7 \mathrm{n}$, facial nerve.

morphine-associated stimuli in nondependent subjects versus post-dependent subjects depending on their projection targets.

\section{VTA: an important site of action for orexin in reward}

Our studies extend previous anatomical studies showing connections from the LH/orexin system to the VTA/dopaminergic system. Phillipson (1979a,b) demonstrated that the hypothalamus has one of the largest inputs to VTA, and the LH projection is substantial. Other studies show that orexin neurons in the hypothalamus innervate VTA (Peyron et al., 1998; Fadel and Deutch, 2002; Yoshida et al., 2006; Vittoz et al., 2008). Functional significance of the orexin system in drug reward was demonstrated by intra-VTA orexin microinjections that reinstated extinguished drug preference (Harris et al., 2005) or cocaine selfadministration (Wang et al., 2009), and by intra-VTA injection of an OXR1 antagonist that suppressed morphine CPP (Narita et al., 2006) or cue-induced reinstatement of cocaine seeking (Mahler et al., 2012). Our data demonstrate an interaction between orexin and VTA systems within the context of morphine abstinence and reward. Animals that underwent protracted abstinence had higher Fos activation in LH orexin neurons that project to VTA than nondependent subjects.

\section{Functional dichotomy in orexin neurons: $\mathrm{LH}$ versus DMH and PFA in drug reward}

Our data support the hypothesis that subpopulations of orexin neurons differ in behavioral properties. In this view, DMH and PFA orexin neurons are involved in arousal, whereas LH orexin cells are related to reward and reinforcement (Harris and AstonJones, 2006; Aston-Jones et al., 2009, 2010). We found that the percentage of VTA-projecting orexin neurons that are Fos activated by morphine CPP in post-dependent animals positively 
correlated with preference scores. This relationship was exclusive to LH orexin neurons. Additionally, LH orexin neurons that project to caudal VTA are engaged only in post-dependent rats, whereas LH orexin neurons that project to rostral VTA are preferentially engaged during preference expressed in nondependent subjects.

We determined that these reward-related activations were specific for VTA-projecting, not LC-projecting, orexin cells. A prior study showed an involvement of orexin receptors in LC in somatic signs of opiate withdrawal (Azizi et al., 2010). However, in our study LH orexin neurons that project to LC were not significantly Fos activated after preference testing. We showed that a higher percentage of LC-projecting orexin neurons express Fos after morphine CPP in DMH and PFA versus $\mathrm{LH}$, which extends the finding that $\mathrm{DMH}$ neurons preferentially project to LC (Aston-Jones et al., 2001; Gompf and Aston-Jones, 2008). However, this increase in activation was not correlated with drug reward. This finding supports the hypothesis that orexin projections to LC play a more substantial role in waking and arousal than reward.

\section{Functional topography: orexin inputs to caudal versus rostral VTA}

Numerous studies have addressed the functional and anatomical heterogeneity in VTA (Ikemoto et al., 1998; Carlezon et al., 2000; Bolaños et al., 2003; Vittoz et al., 2008). We sought to determine whether orexin neurons that project to caudal or rostral VTA were Fos activated by morphine CPP during protracted withdrawal. The percentage of orexin neurons that project to either caudal or rostral VTA that were Fos activated after morphine CPP was significantly greater in post-dependent rats versus nondependent rats. This relationship was only significant for orexin neurons located in LH (for caudal VTA, there was a trend toward an increase in Fos activation also in DMH). Thus, $\mathrm{LH}$ orexin neurons that project to either rostral or caudal VTA have greater activation during the post-dependent state by stimuli previously associated with morphine, further supporting the functional association of LH orexin neurons with drug reward during protracted withdrawal. This observation did not occur for nonretrogradely labeled Fos-activated orexin neurons.

For orexin cells that project to rostral VTA, there was a positive correlation between the number of Fos-activated neurons and morphine preference only in nondependent rats. In contrast, for caudal VTA-projecting orexin neurons, only post-dependent rats exhibited a positive correlation between Fos induction and preference. This difference in activation of orexin neurons as a function of VTA target area supports previous descriptions of two functionally distinct VTA subregions (Olson et al., 2005).

Distinct subpopulations of VTA neurons may reflect regulation of different behaviors via different neural circuits. Le Moal and Simon (1991) demonstrated that the mesocortical dopaminergic system is functionally and pharmacologically different from the mesostriatal dopaminergic system. DA transmission in the medial prefrontal cortex increased in response to spontaneous and precipitated withdrawal, whereas extracellular DA decreased in the accumbens after abstinence from chronic morphine (Bassareo et al., 1995). These data indicate differential roles for two DA systems, affected by withdrawal in a topographical manner. This difference between DA systems after withdrawal may underlie, in part, differences in correlations between Fos and preference in non-dependent animals versus post-dependent animals in our study.

Whereas past studies focused on the differential outputs of DA neurons (e.g., Bassareo et al., 1995), our data highlight differen- tial inputs to VTA. We show that Fos activation in LH orexin neurons varies with whether they target rostral versus caudal VTA, indicating that different populations of orexin neurons are activated by CPP. These functionally distinct orexin projections to VTA are engaged differentially by morphine-associated stimuli in nondependent animals versus post-dependent animals. The interaction of these orexin inputs with other afferents to these VTA regions or areas associated with reward processing requires further study. Additionally, although our data show that VTAprojecting, LH orexin neurons are particularly susceptible to chronic morphine treatment, we acknowledge that these findings do not exhaust the need to investigate the role of other brain regions in morphine dependence.

The state of the animal (motivational, allostatic; Koob and Le Moal, 2001) has a profound influence on the regulation of opiate reward. Our results reveal that nondependent states versus postdependent states influence the regulation of opiate reward by the orexin system. Previous studies (Bechara et al., 1992, 1995; Nader et al., 1996; Nader and van der Kooy, 1997) support the idea of a state-dependent difference in brain regions required for opiate reward, such that DA neurons are needed in animals with previous drug exposure whereas a non-dopaminergic system is required in naive animals (Bechara et al., 1995).

Although there was no significant difference in preference scores for post-dependent and nondependent rats in our study, in contrast with other studies (Harris et al., 2003a, 2006), our current finding was consistent with a previous report (Bechara et al., 1992). The reason for this difference in results with some prior studies is not clear, but may have to do with parametric differences in the CPP procedures. However, our findings point to important differences in orexin regulation of VTA in dependent subjects versus nondependent subjects.

\section{Conclusions}

Several previous reports described the involvement of orexin neurons in drug reinforcement, but the mechanisms through which these neurons may engage the reward systems of the brain during the expression of addictive behaviors remain poorly understood. Our data demonstrate that LH orexin neurons that project to VTA are activated in proportion to preference for morphine reward. Additionally, subpopulations of orexin neurons differ in their projection targets, so that some project to caudal VTA and are engaged in the post-dependent state, whereas others project to rostral VTA and are preferentially engaged during preference expressed in nondependent subjects. Moreover, some orexin neurons project to LC and do not show a clear relationship with morphine preference. These results indicate that LH orexin neurons are functionally heterogeneous, playing differential roles in the morphine reward and nonreward processes. These results call for additional studies to determine the full range of functional heterogeneity in the orexin system.

\section{References}

Aston-Jones G, Harris GC (2004) Brain substrates for increased drug seeking during protracted withdrawal. Neuropharmacology 47 [Suppl] $1: 167-179$.

Aston-Jones G, Chen S, Zhu Y, Oshinsky ML (2001) A neural circuit for circadian regulation of arousal. Nat Neurosci 4:732-738.

Aston-Jones G, Smith RJ, Moorman DE, Richardson KA (2009) Role of lateral hypothalamic orexin neurons in reward processing and addiction. Neuropharmacology 56 [Suppl] 1:112-121.

Aston-Jones G, Smith RJ, Sartor GC, Moorman DE, Massi L, Tahsili-Fahadan P, Richardson KA (2010) Lateral hypothalamic orexin/hypocretin neurons: a role in reward-seeking and addiction. Brain Res 1314:74-90. 
Azizi H, Mirnajafi-Zadeh J, Rohampour K, Semnanian S (2010) Antagonism of orexin type 1 receptors in the locus coeruleus attenuates signs of naloxoneprecipitated morphine withdrawal in rats. Neurosci Lett 482:255-259.

Bassareo V, Tanda G, Di Chiara G (1995) Increase of extracellular dopamine in the medial prefrontal cortex during spontaneous and naloxoneprecipitated opiate abstinence. Psychopharmacology (Berl) 122:202-205.

Bechara A, Harrington F, Nader K, van der Kooy D (1992) Neurobiology of motivation: double dissociation of two motivational mechanisms mediating opiate reward in drug-naive versus drug-dependent animals. Behav Neurosci 106:798-807.

Bechara A, Nader K, van der Kooy D (1995) Neurobiology of withdrawal motivation: evidence for two separate aversive effects produced in morphine-naive versus morphine-dependent rats by both naloxone and spontaneous withdrawal. Behav Neurosci 109:91-105.

Bolaños CA, Perrotti LI, Edwards S, Eisch AJ, Barrot M, Olson VG, Russell DS, Neve RL, Nestler EJ (2003) Phospholipase Cgamma in distinct regions of the ventral tegmental area differentially modulates mood-related behaviors. J Neurosci 23:7569-7576.

Borgland SL, Taha SA, Sarti F, Fields HL, Bonci A (2006) Orexin A in the VTA is critical for the induction of synaptic plasticity and behavioral sensitization to cocaine. Neuron 49:589-601.

Borgland SL, Chang SJ, Bowers MS, Thompson JL, Vittoz N, Floresco SB, Chou J, Chen BT, Bonci A (2009) Orexin A/hypocretin-1 selectively promotes motivation for positive reinforcers. J Neurosci 29:11215-11225.

Boutrel B, Kenny PJ, Specio SE, Martin-Fardon R, Markou A, Koob GF, de Lecea L (2005) Role for hypocretin in mediating stress-induced reinstatement of cocaine-seeking behavior. Proc Natl Acad Sci U S A 102:19168-19173.

Carlezon WA Jr, Haile CN, Coppersmith R, Hayashi Y, Malinow R, Neve RL, Nestler EJ (2000) Distinct sites of opiate reward and aversion within the midbrain identified using a herpes simplex virus vector expressing GluR1. J Neurosci 20:RC62.

Chemelli RM, Willie JT, Sinton CM, Elmquist JK, Scammell T, Lee C, Richardson JA, Williams SC, Xiong Y, Kisanuki Y, Fitch TE, Nakazato M, Hammer RE, Saper CB, Yanagisawa M (1999) Narcolepsy in orexin knockout mice: molecular genetics of sleep regulation. Cell 98:437-451.

de Lecea L, Kilduff TS, Peyron C, Gao X, Foye PE, Danielson PE, Fukuhara C, Battenberg EL, Gautvik VT, Bartlett FS 2nd, Frankel WN, van den Pol AN, Bloom FE, Gautvik KM, Sutcliffe JG (1998) The hypocretins: hypothalamus-specific peptides with neuroexcitatory activity. Proc Natl Acad Sci U S A 95:322-327.

Delfs JM, Zhu Y, Druhan JP, Aston-Jones G (2000) Noradrenaline in the ventral forebrain is critical for opiate withdrawal-induced aversion. Nature 403:430-434.

España RA, Oleson EB, Locke JL, Brookshire BR, Roberts DC, Jones SR (2010) The hypocretin-orexin system regulates cocaine self-administration via actions on the mesolimbic dopamine system. Eur J Neurosci 31:336-348.

España RA, Melchior JR, Roberts DC, Jones SR (2011) Hypocretin 1/orexin $A$ in the ventral tegmental area enhances dopamine responses to cocaine and promotes cocaine self-administration. Psychopharmacology (Berl) 214:415-426.

Fadel J, Deutch AY (2002) Anatomical substrates of orexin-dopamine interactions: lateral hypothalamic projections to the ventral tegmental area. Neuroscience 111:379-387.

Gold LH, Stinus L, Inturrisi CE, Koob GF (1994) Prolonged tolerance, dependence and abstinence following subcutaneous morphine pellet implantation in the rat. Eur J Pharmacol 253:45-51.

Gompf HS, Aston-Jones G (2008) Role of orexin input in the diurnal rhythm of locus coeruleus impulse activity. Brain Res 1224:43-52.

Harris GC, Aston-Jones G (2001) Augmented accumbal serotonin levels decrease the preference for a morphine-associated environment during withdrawal. Neuropsychopharmacology 24:75-85.

Harris GC, Aston-Jones G (2003a) Enhanced morphine preference following prolonged abstinence: association with increased Fos expression in the extended amygdala. Neuropsychopharmacology 28:292-299.

Harris GC, Aston-Jones G (2003b) Altered motivation and learning following opiate withdrawal: evidence for prolonged dysregulation of reward processing. Neuropsychopharmacology 28:865-871.

Harris GC, Aston-Jones G (2006) Arousal and reward: a dichotomy in orexin function. Trends Neurosci 29:571-577.
Harris GC, Aston-Jones G (2007) Activation in extended amygdala corresponds to altered hedonic processing during protracted morphine withdrawal. Behav Brain Res 176:251-258.

Harris GC, Wimmer M, Aston-Jones G (2005) A role for lateral hypothalamic orexin neurons in reward seeking. Nature 437:556-559.

Ikemoto S, Murphy JM, McBride WJ (1998) Regional differences within the rat ventral tegmental area for muscimol self-infusions. Pharmacol Biochem Behav 61:87-92.

Koob GF, Le Moal M (2001) Drug addiction, dysregulation of reward, and allostasis. Neuropsychopharmacology 24:97-129.

Korotkova TM, Sergeeva OA, Eriksson KS, Haas HL, Brown RE (2003) Excitation of ventral tegmental area dopaminergic and nondopaminergic neurons by orexins/hypocretins. J Neurosci 23:7-11.

Lawrence AJ (2010) Regulation of alcohol-seeking by orexin (hypocretin) neurons. Brain Res 1314:124-129.

Lawrence AJ, Cowen MS, Yang HJ, Chen F, Oldfield B (2006) The orexin system regulates alcohol-seeking in rats. Br J Pharmacol 148:752-759.

Le Moal M, Simon H (1991) Mesocorticolimbic dopaminergic network: functional and regulatory roles. Physiol Rev 71:155-234.

Li SX, Liu LJ, Jiang WG, Sun LL, Zhou SJ, Le Foll B, Zhang XY, Kosten TR, Lu L (2010) Circadian alteration in neurobiology during protracted opiate withdrawal in rats. J Neurochem 115:353-362.

Lin L, Faraco J, Li R, Kadotani H, Rogers W, Lin X, Qiu X, de Jong PJ, Nishino S, Mignot E (1999) The sleep disorder canine narcolepsy is caused by a mutation in the hypocretin (orexin) receptor 2 gene. Cell 98:365-376.

Mahler SV, Smith RJ, Aston-Jones G (2012) Interactions between VTA orexin and glutamate in cue-induced reinstatement of cocaine seeking in rat. Psychopharmacology, in press.

Nader K, van der Kooy D (1997) Deprivation state switches the neurobiological substrates mediating opiate reward in the ventral tegmental area. J Neurosci 17:383-390.

Nader K, Bechara A, van der Kooy D (1996) Lesions of the lateral parabrachial nucleus block the aversive motivational effects of both morphine and morphine withdrawal but spare morphine's discriminative properties. Behav Neurosci 110:1496-1502.

Nakamura T, Uramura K, Nambu T, Yada T, Goto K, Yanagisawa M, Sakurai $\mathrm{T}$ (2000) Orexin-induced hyperlocomotion and stereotypy are mediated by the dopaminergic system. Brain Res 873:181-187.

Narita M, Nagumo Y, Hashimoto S, Narita M, Khotib J, Miyatake M, Sakurai T, Yanagisawa M, Nakamachi T, Shioda S, Suzuki T (2006) Direct involvement of orexinergic systems in the activation of the mesolimbic dopamine pathway and related behaviors induced by morphine. J Neurosci 26:398-405.

Olson VG, Zabetian CP, Bolanos CA, Edwards S, Barrot M, Eisch AJ, Hughes T, Self DW, Neve RL, Nestler EJ (2005) Regulation of drug reward by cAMP response element-binding protein: evidence for two functionally distinct subregions of the ventral tegmental area. J Neurosci 25:5553-5562.

Paxinos G, Watson C (2007) The rat brain, in stereotaxic coordinates. Amsterdam: Elsevier Academic.

Peyron C, Charnay Y (2003) [Hypocretins/orexins and narcolepsy: from molecules to disease]. Rev Neurol (Paris) 159:6S35-41.

Peyron C, Tighe DK, van den Pol AN, de Lecea L, Heller HC, Sutcliffe JG, Kilduff TS (1998) Neurons containing hypocretin (orexin) project to multiple neuronal systems. J Neurosci 18:9996-10015.

Peyron C, Faraco J, Rogers W, Ripley B, Overeem S, Charnay Y, Nevsimalova S, Aldrich M, Reynolds D, Albin R, Li R, Hungs M, Pedrazzoli M, Padigaru M, Kucherlapati M, Fan J, Maki R, Lammers GJ, Bouras C, Kucherlapati R, Nishino S, Mignot E (2000) A mutation in a case of early onset narcolepsy and a generalized absence of hypocretin peptides in human narcoleptic brains. Nat Med 6:991-997.

Phillipson OT (1979a) Afferent projections to the ventral tegmental area of Tsai and interfascicular nucleus: a horseradish peroxidase study in the rat. J Comp Neurol 187:117-143.

Phillipson OT (1979b) A Golgi study of the ventral tegmental area of Tsai and interfascicular nucleus in the rat. J Comp Neurol 187:99-115.

Richards JK, Simms JA, Steensland P, Taha SA, Borgland SL, Bonci A, Bartlett SE (2008) Inhibition of orexin-1/hypocretin-1 receptors inhibits yohimbineinduced reinstatement of ethanol and sucrose seeking in Long-Evans rats. Psychopharmacology 199:109-117.

Sakurai T, Amemiya A, Ishii M, Matsuzaki I, Chemelli RM, Tanaka H, 
Williams SC, Richarson JA, Kozlowski GP, Wilson S, Arch JR, Buckingham RE, Haynes AC, Carr SA, Annan RS, McNulty DE, Liu WS, Terrett JA, Elshourbagy NA, Bergsma DJ, et al. (1998) Orexins and orexin receptors: a family of hypothalamic neuropeptides and $G$ protein-coupled receptors that regulate feeding behavior. Cell 92:1 page following 696.

Scammell TE, Estabrooke IV, McCarthy MT, Chemelli RM, Yanagisawa M, Miller MS, Saper CB (2000) Hypothalamic arousal regions are activated during modafinil-induced wakefulness. J Neurosci 20:8620-8628.

Smith RJ, See RE, Aston-Jones G (2009) Orexin/hypocretin signaling at the orexin 1 receptor regulates cue-elicited cocaine-seeking. Eur J Neurosci 30:493-503.

Smith RJ, Tahsili-Fahadan P, Aston-Jones G. (2010) Orexin/hypocretin is necessary for context-driven cocaine-seeking. Neuropharmacology 58:179-184.
Vittoz NM, Berridge CW (2006) Hypocretin/orexin selectively increases dopamine efflux within the prefrontal cortex: involvement of the ventral tegmental area. Neuropsychopharmacology 31:384-395.

Vittoz NM, Schmeichel B, Berridge CW (2008) Hypocretin/orexin preferentially activates caudomedial ventral tegmental area dopamine neurons. Eur J Neurosci 28:1629-1640. Wang B, You ZB, Wise RA (2009) Reinstatement of cocaine seeking by hypocretin (orexin) in the ventral tegmental area: independence from the local corticotropin-releasing factor network. Biol Psychiatry 65:857-862.

Yoburn BC, Chen J, Huang T, Inturrisi CE (1985) Pharmacokinetics and pharmacodynamics of subcutaneous morphine pellets in the rat. J Pharmacol Exp Ther 235:282-286.

Yoshida K, McCormack S, España RA, Crocker A, Scammell TE (2006) Afferents to the orexin neurons of the rat brain. J Comp Neurol 494:845-861. 